\title{
The Relationship between Experiential Learning Styles and the Immediate and Delayed Retention of English Collocations among EFL Learners
}

\author{
Afsaneh Mohammadzadeh ${ }^{1}$ \\ ${ }^{1}$ Payame Noor University, Iran \\ Correspondence: Afsaneh Mohammadzadeh, Payame Noor University, Iran. E-mail: \\ Mohammadzadeh_af@yahoo.com
}

Received: September 11, 2012 Accepted: October 24, 2012 Online Published: October 31, 2012

doi:10.5539/elt.v5n12p121 URL: http://dx.doi.org/10.5539/elt.v5n12p121

\begin{abstract}
This study was carried out to find out if there was any significant difference in learning English collocations by learning with different dominant experiential learning styles. Seventy-five participants took part in the study in which they were taught a series of English collocations. The entry knowledge of the participants with regard to collocations items of the treatment as well as the difficulty level of the items were controlled. Upon the completion of the treatment, participants' retention of the items was measured in an immediate and a delayed recognition type tests. The results showed a statistically significant difference among the four experiential learning style groups. The findings offer a number of implications with regard to the teaching and learning of English collocations.
\end{abstract}

Keywords: collocation, experiential learning style, retention

\section{Introduction}

It might not need much experience in language learning and teaching to come to the conclusion that lexicon study is of great importance to and a central part of language learning. Some scholars have even stressed that, no matter how skilled students are at grammar, communication will cease without the words to convey meaning (e.g., McCarthy, 1990). Milton (2009) comments that vocabulary is not an elective or insignificant component in the language acquisition process insomuch as "words are the building blocks of language and without them there is no language" (p. 3).

In the history of language pedagogy, vocabulary learning has been marginalized in teaching and learning of foreign and second languages. O'Dell (1997, cited in Milton, 2009) states that, throughout the 1970s and 1980s, vocabulary and lexis were absent from main books on the syllabus and theory of language teaching. This apparent neglect of vocabulary teaching was largely due to the linguists' great emphasis on syntax and phonology over vocabulary, under the assumption that vocabulary acquisition could take care of itself (Decarrico, 2001). Nonetheless, by the late 1970s and early 1980s, many voices started to defy the view that vocabulary can be absorbed naturally. This resulted in the revival of interest in vocabulary teaching and the recognition of the significant role of vocabulary during language acquisition (Decarrico, 2001).

Within the field of vocabulary, researchers have emphasized the importance of word combinations, also known as formulaic language. Conklin and Schmitt (2007) indicate that lexical combinations are very common in language discourse and differentiate the speech of native and non-native speakers. Erman and Warren (2000), for instance, analyzed native speakers' written and spoken discourses and determined that formulaic expressions represent $58.6 \%$ of the spoken English discourse and $52.3 \%$ of the written discourse. Foster (2001), who was looking for formulaic language in informal natives' speech, found that $32.3 \%$ of speech consists of formulaic expressions. Furthermore, Howarth (1998), when looking at 238,000 words of academic writing, claims that $31-40 \%$ was composed of collocations and idioms. Thus, all these studies show that formulaic language forms a large part of any discourse (Conklin \& Schmitt, 2007).

As a subcategory of formulaic language, the notion of collocation has received considerable attention in the field of foreign language learning during the last few decades (Gitsaki, 1999, Webb \& Kagimoto, 2009). Firth (1957) is considered to be the first to explicitly introduce the term collocation (Gitsaki, 1999). In defining collocation, 
Firth argues that a word is recognized by the words that accompany it. He exemplifies this by using the English words dark night as an example of collocation. He clarifies that one of the meanings of the word night allows its collocability with dark and vice versa (Zughoul \& Abdul-Fattah, 2003). Subsequent researchers, who have studied the occurrence of collocation, dealt with its definition in various ways, as will be discussed in detail in Chapter II. Yet, there is still no precise non-controversial, fixed definition of a collocation (Fontenelle, 1994).

Learning collocations is regarded as an important and crucial part in L2 acquisition because the meaning of a lexical item has much to do with other lexical items that are combined with it. "Not only do these associations assist the learner in committing these words to memory, they also aid in defining the semantic area of a word" (Nattinger, 1988, p. 7). Ellis (2001, cited in Nation, 2001) also takes a strong position on the importance of collocational knowledge by stating that it is the essence of language learning. Along the same lines, McCarthy (1990) argues that collocation is "an important organizing principle in the vocabulary of any language" (p. 12). Additionally, the significance of collocation can be clearly seen and perceived when observing the speech and writing of foreign learners who often fail to produce collocations in the proper order. This shows how important the knowledge of collocations is and calls for perception and concern by both L2 instructors and students (Carter \& MacCarthy, 1988). Due to this importance, general-purpose learners' dictionaries (which include a fair number of collocations), monolingual dictionaries of collocation and bilingual dictionaries of collocation have been compiled for the sake of helping foreign language learners deal with the difficulties they encounter "in vocabulary learning in general and collocations in particular" (Al-zahrani, 1998, p. 26)

Learning collocations or any other language form for that matter can be viewed from a number of perspectives. When we look at this issue from the perspective of the learner, the learner-related factors begin to attract our attention. So, if certain learners choose to learn collocations through a certain procedure, the logical question is why this procedure has been chosen and not another one. Traditionally, one of the determining factors in such decisions has been the learners' cognitive or learning styles. Students preferentially take in and process information in different ways: by seeing and hearing, reflecting and acting, reasoning logically and intuitively, analyzing and visualizing, and so on depending on what inventory of learning style is being used for assessment and which theory serves as the basis of such assessment.

One of the most interesting innovations in the field of learning style is one called the Kolb Learning Style Inventory. This inventory differs from other tests of learning style and personality used in education by being based on a comprehensive theory of learning and development (Kolb, 1999). Experiential learning theory (ELT) draws on the work of prominent twentieth century scholars who gave experience a central role in their theories of human learning and development-notably John Dewey, Kurt Lewin, Jean Piaget, William James, Carl Jung, Paulo Freire, Carl Rogers, and others-to develop a holistic model of the experiential learning process and a multi-linear model of adult development.

\section{Background}

According to Nation (2001), the average lexicon of an intermediate foreign language learner should surpass the threshold of 3,000-collocations for reading unfamiliar texts. However, in the majority of foreign language environments, there exists a large gap between instructional strategies and learners' outcomes in English collocation acquisition (Conklin \& Schmitt, 2007). Therefore, it can be inferred that finding out what factors might play determining roles in the retention of collocation items should be considered a vital mission for English teachers in a foreign, in this case an Iranian, context of language learning and teaching.

Being a non-native speaker, the researcher has experienced the challenges that collocations pose. Despite having studied English for many years, the researcher personally failed to achieve relatively satisfactory results on a collocation test. This indicates that achieving an advanced collocation level takes a great deal of time and effort. In addition, this collocation-related episode sparked the researcher's interest in the topic to find ways to facilitate the learning of collocation for Iranian students.

In this study, the researcher intends to find out if people with certain experiential learning styles have any advantage or disadvantage over other styles in retaining English collocations in the short and longer terms.

The possible results of this study could contribute to the improvement of instruction in the teaching and learning of foreign languages in general and the teaching and learning of English as a foreign language in particular.

The significance of this study can be argued on both theoretical and practical grounds. At the theoretical level, the study aims at contributing to the growing body of collocation instruction studies. It provides the much-needed information on the deferential effect of different experiential learning styles on FL immediate and delayed collocation retention. This study provides practical information for collocation material designers in 
recognizing the significance of the role of a certain learner's experiential learning style in facilitating FL collocation learning. It also informs language teachers and administrators who need to make solid decisions about collocation teaching programs to enhance L2 collocation retention.

The significance of this study can also be established from a rather different perspective, i.e., its relative novelty. This study can be called new in that it differs from previous studies in several ways: It evaluates the immediate retention of collocations among participants in an EFL setting; to the best of the researcher's knowledge, only few studies have examined the collocation retention of Persian-speaking learners of English in an EFL setting and no study has so far studied the relationship between experiential learning styles and collocation retention. The intent of the current study is to contribute to the extant research in general, and to the limited studies of collocations on Persian language speakers in particular.

\subsection{What Is a Collocation?}

Collocation has proved to be difficult to define. For example, Benson, Benson, and Ilson (1986), provided a general definition of collocations: "In English, as in other languages, there are many fixed, identifiable, non-idiomatic phrases and constructions. Such groups of words are called recurrent combinations, fixed combinations or collocations" (p. ix). According to Howarth (1998), collocation is the co-occurrence of lexical items with a grammatical function as components of sentences while Lewis (2000) defines collocation as lexical items that co-occur naturally in statistically important ways. In a reaction to the definition by Lewis, Nation (2001) counterargues that it is not satisfactory to simply define collocation as a cluster of lexical items that are used together repeatedly. Instead he presents this definition to make up for the shortcomings of previous ones: "collocations are closely structured groups whose parts frequently or uniquely occur together. We would also expect collocations to contain some element of grammatical or lexical unpredictability or inflexibility" (p. 324).

\subsection{Empirical Studies on Collocation}

There have been a number of interesting works in recent years focused on the collocational knowledge of learners. One of the earliest works was carried out by Channell (1981). The findings of his study showed that although the learners were familiar with the majority of the collocational items, they were not able to actively use them in meaningful contexts. One of his conclusions is that the teacher should present a large number of frequent collocation items when the learner first tries to learn a vocabulary item. He maintains this strategy is more applicable to those learners who do not have the chance to interact with native speakers and use the items in real communication.

One of the other interesting works is done by Aghbar (1990) who used a long cloze test. The results indicated that the faculty members generated the most suitable sentence while ESL learners produced a limited number of collocational items. According to Aghbar, the ESL learners performed less than expected mainly because they had not acquired the necessary language chunks that make it possible for us to produce fluent and idiomatic discourse.

Some researchers have examined the learners' developmental patterns of collocational knowledge. According to Gitaski (1996), ESL learners' bad performance on collocational tests was not due to their inadequate vocabulary acquisition but rather to the "lack of acquisition of those language chunks that make discourse fluent and idiomatic" (p. 6).

One of the other objectives of collocational studies has been the development patterns of ESL/EFL learners. Gitsaki's study (1996) claimed that there is a developmental process that L2 learners follow in learning collocations and this process can be described and analyzed. One of her findings is that grammatical collocations, generally, are easier to acquire than lexical collocations. Moreover, among the numerous types of collocation used in the study, verb-noun lexical collocations (e.g., take actions) were the most difficult and highly challenging for all subjects in different tasks. Gitsaki assumes that the cause of this situation is the arbitrariness and unpredictability of such collocations making is hard for L2 learners to acquire them. Finally, she concluded that, EFL and ESL learners' collocational knowledge expands steadily along with the development of their proficiency level. Gitaski enumerates a number of factors that affect collocation acquisition such as familiarity, frequency of the input, and salience of the collocation types.

In 2002, Hsu attempted to ascertain whether the teaching of lexical collocations would improve the development of Taiwanese EFL learners' collocational proficiency in a short intensive course. The obtained data showed a positive relationship between learners' use of lexical collocations and their overall language proficiency. Hsu also corroborates Gitsaki's conclusion that there are some possible factors that affect learners' ability to acquire collocations. Among these factors are the degree of idiomaticity, differences of L1/L2, instruction type, and 
language learning beyond the classroom.

One of the other areas studies with regard to collocation acquisition is the collocational errors that L2 learners might commit. In an attempt to discover the effects the learners' might have on L2 learners' comprehension and production of collocations, Biskup (1992) carried out a comparative study. The participants in this study translated English lexical collocations into German and Polish. One of the more interesting findings of this study is with regard to the role of L1 interference which indicates that L1 had a strong influence on the participants' production of collocations. The study revealed that the errors made by Polish students were due to either loan translations or extending L2 meaning of collocations on the basis of L1 words.

\subsection{Learning Styles}

One of the variables that can potentially affect a learner's degree of learning is his or her dominant learning style(s). There have been many attempts at defining learning styles. For example, learning styles is sometimes defined as a preference for one particular learning modality (Ehrman \& Oxford, 1988). It is also defined as "learners' consistent ways of responding to and using stimuli in the context of learning" (Claxton and Ralston, 1978, p. 7). Kinsella puts forward a rather different definition (1995, p. 171) by describing it as "learners' natural, habitual, and preferred ways of absorbing, processing, and retaining new information and skills which persist regardless of teaching methods or content area."

One of the areas of interest in this regard has been the mismatches between learning styles and teaching methodologies which are said to be one of the factors that affect learning difficulties (Ehrman \& Oxford, 1988). The nature of learning a language is so complex that makes investigating the role of learning styles an indispensible endeavor.

Researchers have long been interested in the role of learning styles in educational achievement. As far back as 1945, Lewenfeld studied visual versus auditory preferences, however, the concept of learning style is still poorly understood. The main cause is the confusion created by a wide variation in the scale and scope of learning, school achievement, and other types of behavior that are assumed by plentiful learning style terms (Nel, 2008). In his perceptual style preference inventory, Reid (1998) identified four basic style preferences: visual (reading charts, for example), auditory (for instance listening to lectures), kinesthetic (such as physical activity), and tactile (for instance doing laboratory experiments). Later, the dimensions of group versus individual learning preferences were added to form the inventory known as the Perceptual Learning Style Preference Questionnaire.

\subsection{Theory of ELT}

One of the widely investigated learning styles is known as the Experiential Learning Styles which is based on the Experiential learning theory (ELT). In this theory, great importance is attached the role that experience plays in human learning and development. The theory developed out of the works of a number of figures including John Dewey, Kurt Lewin, Jean Piaget, William James, Carl Jung, Paulo Freire, and Carl Rogers. The theory, described in detail in Experiential Learning: Experience as the Source of Learning and Development (Kolb 1984), is built on six propositions that are shared by the scholars mentioned above (Kolb, 1984). The summary of these propositions are: 1. Learning is best conceived as a process, not in terms of outcomes; 2. All learning is relearning; 3 . Learning requires the resolution of conflicts between dialectically opposed modes of adaptation to the world; 4. Learning is a holistic process of adaptation to the world; 5. Learning results from synergetic transactions between the person and the environment; and 6. Learning is the process of creating knowledge.

This theory defines learning as "the process whereby knowledge is created through the transformation of experience. Knowledge results from the combination of grasping and transforming experience" (Kolb 1984, p.41). In this model, there are two modes of grasping experience, that is, Concrete Experience (CE) and Abstract Conceptualization(AC). It also has two modes of transforming experience-Reflective Observation (RO) and Active Experimentation (AE). The result of these two choices produces our preferred learning style, hence the two-by-two matrix further below (Table 1). By choosing one of the two ways of grasping the experience, we determine our approach to it; on the other hand, by choosing our way to transform the experience into something meaningful and practical, we set our emotional response to that experience (Kolb, 1984). According to ELT, the learning cycle that results from these choices is different for different individuals' learning style and learning context (Kolb, 1984). 
Table 1. Learning styles matrix

\begin{tabular}{llll}
\hline & DOING (Active Experimentation & WATCHING & (Reflective \\
& $-\mathrm{AE})$ & Observation - RO) & \\
FEELING (Concrete Experience - CE) & accommodating (CE/AE) & diverging (CE/RO) & \\
$\begin{array}{lll}\text { THINKING } \\
\text { Conceptualization - AC) }\end{array}$ & (Abstract & converging (AC/AE) & assimilating (AC/RO) \\
\hline
\end{tabular}

\subsection{Features of the Four Learning Styles}

As the matrix above indicates, people can be divided roughly into four different learning styles based on their approach to obtain knowledge: Divergers, Assimilators, Convergers, and Accommodators. Shortly, according to Kolb (1984), and Kolb, Boyatzis, and Mainemelis, (2001), Divergers can look at things from different perspectives, they prefer to watch rather than do. They are interested in people, are imaginative, emotional, and tend to be talented with regard to arts. On the other hand, convergers are described as people capable of solving problems who are less concerned with people and interpersonal relations. They are best at finding practical uses for ideas and theories and making decisions by finding solutions to questions and problems. People with a converging learning style like to experiment with novel ideas, to simulate, and to create practical applications for new ideas.

Assimilators, according to Kolb (1984), and Geiger (1992), are people who prefer a concise, logical approach. To them, ideas and concepts are more important than people. They better learn through clear explanation rather than practical activity. Moreover, they are more attracted to reading, lectures, exploring analytical models. To learn better, they need time to think things through. Conversely, accommodators rely on intuition rather than logic. They tend to make use of other people's analysis and are good at taking a practical, experiential approach to issues. They bravely face new challenges and experiences by mainly acting on instincts rather than reasoning.

\subsection{Experiential Learning Styles in Language Studies}

According to Castro and Peck (2005) who administered the Kolb Learning Styles Inventory to students of regular and modified Spanish classes in an American university, as part of a longitudinal study on learning styles and foreign language learning difficulties, a learner's preferred learning style can potentially hamper or aid achievement in the foreign language instructional environments. These researchers also contend that such information can assist researchers, instructors, as well as the learners themselves in reaching academic goals.

\section{Method}

\subsection{Participants}

The data for this study were collected from a total of 75 learners of English as a foreign language. They studied English at the intermediate level in four different branches of the same language institute in Iran, during the spring of 2012. The participants were from different branches for a couple of reasons. First of all, a geographically wider sampling, although intact group sampling, would better represent what we label in this study as an Iranian EFL learner. Furthermore, the limited number of classes in each branch and the limited number of teachers willing to cooperate in each branch forced the researcher to recruit teachers from different branches. The 75 participants came from four different classes. As the institute deploys a set of rather systematic standardized placement tests, all the participants are assumed to belong to roughly the same proficiency level. It should also be mentioned that due to policy of the institute, all the participants were inevitably female learners who ranged in age between 17 and 35. Although this age range might encourage some researchers to include age as a moderator variable, this study did not take this option into consideration.

\subsection{Design of the Study}

This study can be considered a quasi-experimental with pretest, treatment and posttest design. As the study was to be carried out in a private language institute, the researcher had no jurisdiction on randomly selecting learners.

\subsection{Instrument LSI}

In order to collect data on the second or better say the dependent variable of the study, that is, the experiential learning style, a standardized questionnaire called LSI-IIa was adopted and translated into Persian to make sure proficiency issues would not affect responses. This instrument, the Learning Style Inventory, was developed by David Kolb in 1976. It was designed as a self-assessment test to measure learners' preferred learning modes, and 
consequently their learning styles. The third version of this 12 statement inventory, the Learning Styles Inventory Ha (LSI-IIa) (Kolb, 1999), has been refined so it demonstrates acceptable reliabilities and other psychometric properties and was suitable for investigations evaluating learning styles (Veres, Sims, \& Locklear, 1991). Although the latest version of LSI, version 3.1, has been produced, it is available only for commercial purposes and the researcher is charged according to the number of participants of the study.

This inventory is designed to gauge the degree to which learners display the different learning styles that are explicated by the experiential learning theory. The version of the inventory, as briefly mentioned above, is LSI-IIa. As Kolb (1999) puts it, all versions of the LSI have similar formats which consist of a short 9 to 12 item questionnaire requiring learners to rank four sentence endings corresponding to the four learning modes-Concrete Experience (e.g., experiencing), Reflective Observation (reflecting), Abstract Conceptualization (thinking), and Active Experimentation (doing).

One interesting feature of LSI, which distinguishes it from most other formats, is that it is a forced-choice format that ranks an individual's relative choice preferences among the four modes of the learning cycle. This forced-choice format of the inventory is not a personal choice and is determined by the theory of experiential learning and by the basic primary purpose of the questionnaire.

\subsection{Procedure}

Following the selection of the four classes, the respective teachers needed to undergo short training and as two of them were from distant cities, telephone and email served as the main media for their briefing. After establishing uniformity in methodology among teachers, the researcher asked the four teachers to deploy the following procedure: The first step was the administration of the LSI among all participants. As mentioned above, this inventory, LSI II-a, consists of 12 sentences with a choice of four endings for each. Participants were asked to rank each ending in a scale of 1 to 4 ( 1 being the least favored and 4 the most favored) according to what sentence best describes how they learn most effectively. Students were given clear instructions on how to proceed and individual help was offered to work through the different parts of the inventory to make sure all students followed instructions correctly and that they had no difficulty in comprehending items. The completed questionnaires were returned to the researcher upon completion. The second step was the administration of the pretest. In this test, a list of 150 lexical English collocation items was administered to learners. The learners were asked to write down the Persian equivalents of items. The items that were even partially answered by more than five students were deleted from the instruction program. This would obviate the possibility of attributing their gains in treatment to prior knowledge. Naturally, the four classes would go by different final lists since the data came from four different groups though there were supposed to be from almost the same proficiency levels. The obvious problem, however, in such a design is the possible different difficulty level of the final list for different groups. To address this problem, the researcher did her best to produce the original list of collocation items with almost similar difficulty level. To do, the number of syllables and the composition of each item were taken into consideration. Furthermore, two highly proficient teachers of English as a foreign language were asked to review the list and mark off the too easy or too difficult items.

The treatment on collocation formed only part of the teachers' instruction since they had to cover the material designated by the institute as well. It basically consisted of presenting the collocation items through exposing participants to a number of pre-fabricated sentences containing the intended items. The teachers explained the meaning of collocational items using different techniques, asking some students to put them into new contexts as a way of securing the learning of the items. Moreover, all participants were asked to produce one novel sentence for each item and present them to the teacher the following session for feedback. Fortunately, as this treatment provided the participants with useful extracurricular activity, almost all learners displayed very active cooperation in this regard which greatly aided the researcher in collecting relevant data.

After a whole semester of instruction which was about two and a half months, a total of 20 sessions, the participants took a final test of 40 multiple-choice items in which they were asked to complete certain sentences with choices of collocation items to measure their immediate recall. An equivalent form was administered to the same participants two weeks later (at the beginning of their next term in the institute) to measure their delayed retention of the collocation items.

\subsection{Data Analysis}

The obtained data from the immediate retention tests yielded a maximum score of 40 for each participant. The same test items were deployed for the delayed retention but in different contexts. Similar number of words and syntactic complexity were used as measure of equal difficulty of both tests. The data of the two tests were on the interval scale but to make sure if other assumptions for the use of parametric tests exist, Kolmogrov-Smirnov test 
was applied. Upon confirmation of the possibility of using parametric tests, the obtained data from the LSI were used to divide the participants into four groups of convergers, divergers, assimilators and accommodators. Repeated measure one-way ANOVAs were deployed to detect any significant difference in retention among the four experiential learning style groups. Post-hoc tests were also used to find the exact location of any possible significant difference through SPSS 20. Finally, the .05 level of significance was set for the rejection of the null hypotheses.

\section{Results}

This study was conducted to find out if there is any significant difference in immediate and delayed retention of English lexical collocational items among the four experiential learning style groups. Table 2 below displays the descriptive statistics of the distribution of means and standard deviations of the four learning style groups. The same data are graphically presented in Figure 1. As it can be clearly observed, the group divergers not only outnumbered the other groups in terms of member size but also displayed a higher mean in both immediate and delayed tests. However, to make sure that this difference is statistically significant, repeated measure one-way ANOVA and post-hoc tests were computed.

Table 2. Descriptive data

\begin{tabular}{llllll}
\hline & Group Means & Std. Deviations & $\mathrm{N}$ & percentage \\
\hline Test 1 & convergers & 23.7222 & 2.58515 & 17 & $22 \%$ \\
& divergers & 28.6957 & 2.26612 & 23 & $30 \%$ \\
& assimilators & 22.8947 & 2.74661 & 19 & $25 \%$ \\
& accommodators & 21.7333 & 2.79151 & 16 & $21 \%$ \\
& Total & 24.6400 & 3.70770 & 75 & \\
Test 2 & convergers & 19.1667 & 2.52132 & 17 & $24 \%$ \\
& divergers & 25.3913 & 2.11792 & 22 & $31 \%$ \\
& assimilators & 19.2632 & 2.62133 & 18 & $25 \%$ \\
& accommodators & 16.4000 & 2.26148 & 15 & $20 \%$ \\
& Total & 20.5467 & 4.15020 & 70 & \\
\hline
\end{tabular}

To statistically find out the possible differential effect of treatment, i.e., collocation instruction, for the four different experiential learning style groups, the data were submitted to two one-way ANOVAs (this was carried out after making sure the assumptions of parametric statistics were met). The first ANOVA for the immediate recall test yielded $\mathrm{F}(3,71)=16.61, \mathrm{p}=.000$. This result rejects the null hypothesis that there is no significant difference in recall of collocation items. However, to locate where the difference lies among the four style groups, a post-hoc test was carried out which indicated the main difference to be between group 2, divergers, and the other three groups. In other words, no significant difference was found among convergers, assimilators, and accommodators.

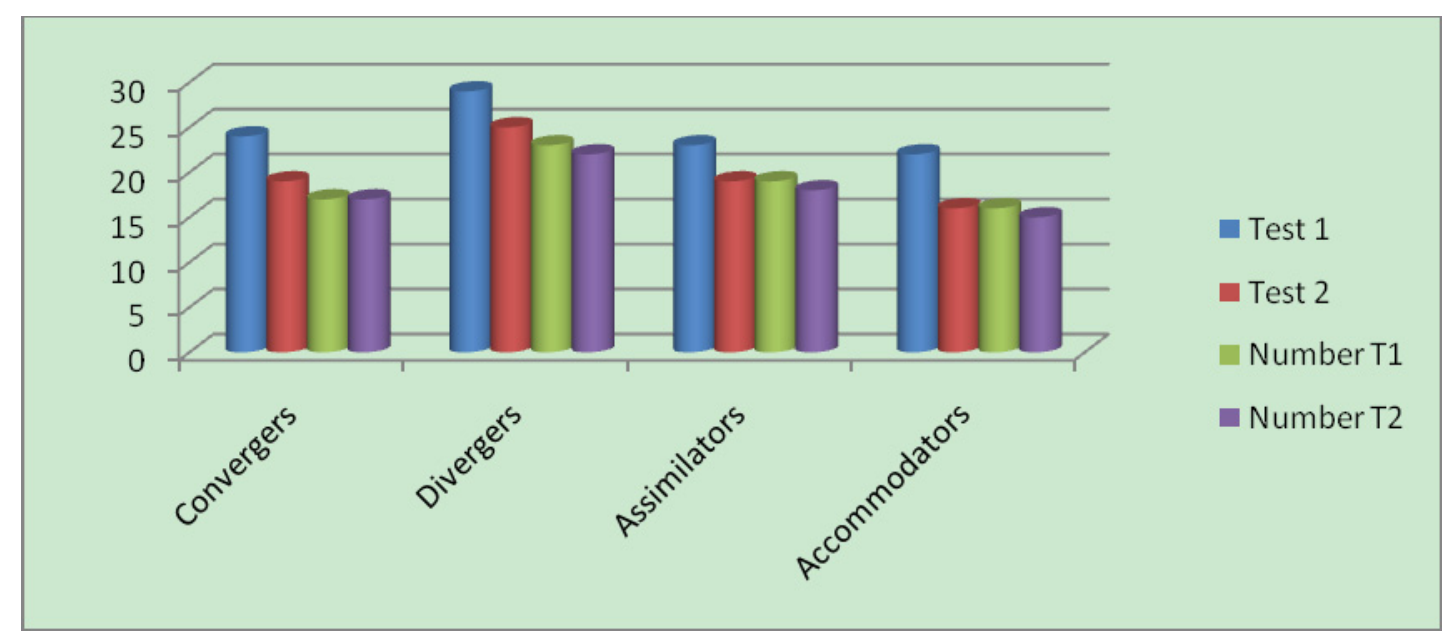

Figure 1. Distribution of style groups and test scores 
Moreover, as indicated earlier, a follow-up test was administered to the same participants two weeks after the immediate test. It should be noted, however, that five of the participants did not show up for the delayed post-test: $\mathrm{F}(3,66)=12.55, \mathrm{p}=.000$, thus again rejecting the hypothesis of no difference among the four learning style groups. Interestingly, the post-hoc test reconfirmed the results for the immediate test, that is, the divergers showed to be more successful than all the other three groups that showed no significant difference among them.

\section{Discussion and Conclusion}

Table 2 displays that in the immediate test out of 75 participants, convergers comprised $22 \%$, assimilators $25 \%$, divergers $30 \%$, leaving about $21 \%$ for accommodators. This distribution was quite different from the percentages found by Willing (1988) where accommodators represented the largest group in a foreign language learning experiment. However, the divergers comprising the largest group in this study shows an interesting match with the report by Kolb (1981) on information derived from the Carnegie Commission study of graduate students and faculty-that foreign language graduate students and faculty fell mostly in the diverger category.

The percentages of this study also show differences as well as similarities with those obtained in fields other than language learning. For example, Kruzich, Friesen, and Soest (1986) conducted a study of student and faculty learning styles in social work at two universities and two private colleges and found significant learning style differences among undergraduate students, graduate students, field instructors, and social work faculty. Generally, faculty most often had converging learning styles, whereas the majority of graduate students and field instructors were diverging learners. This part also shows a similarity to data obtained in the present study.

The results of the study showed a statistically significant edge in both immediate and delayed tests for the experiential learning group labeled as divergers. This indicates that a learner's experiential learning style does make a difference in learning English collocations, at least as far as the circumstances of this study are concerned. However, in order to be better able to interpret the findings, a review of the characteristics of divergers seems to be required.

According to Kolb, (1984), and Kolb, et al., (1999), divergers are able to look at things from different perspectives. They are sensitive. They prefer to watch rather than do, tending to gather information and use imagination to solve problems. They are best at viewing concrete situations from several different viewpoints. Kolb called this style Diverging because these people perform better in situations that require ideas-generation, for example, brainstorming. People with a diverging learning style have broad cultural interests and like to gather information. They are interested in people, tend to be imaginative and emotional, and tend to be strong in the arts. People with the diverging style prefer to work in groups, to listen with an open mind and to receive personal feedback. Finally, it should be mentioned that this style is a combination of concrete experience as the strategy for perceiving experience and reflective observation for transforming it.

As mentioned above, one of the characteristics of divergers is that they generally prefer to watch rather than do. As a generalization to language learning, one might conclude that they are better in recognition type activities, as it was the case with this study's multiple-choice test format, than in productive activities. To arrive at a firmer conclusion in this regard, we need to repeat the present study with more diverse test formats including recognition as well as production items. Moreover, the diverger prefers to approach learning or grasp knowledge through concrete experience or feeling. In other words, such learners form their experiences and deal with situations in a personal manner and value their own feelings over thinking. They also transform their experiences through reflective observation. According to Geiger (1992), divergers are best at viewing existing situations from many different points of view. This point can help us greatly to justify their relative success in learning collocations of a foreign language. Learning and retaining a collocation item seems to require a focus on form which, according to Long (1991) is actually a delicate combination of a focus on meaning and occasional focus on grammatical, lexical, etc. points. As they prefer to view situations from various perspectives, focus on form enables them to view language points from both a holistic as well as an analytic point of view thus being able to better grasp and transform their linguistic experiences. Geiger (1992) also states that divergers perform better in situations that need generating new ideas and brainstorming and that their strength lies in imaginative ability and awareness of meaning and values. They tend to have broad cultural interests, are interested in people, and are feeling oriented. From among these characteristics, we can take imaginative ability and awareness of meaning as somehow corresponding to the approach known as focus on form in which learners are required to use their background knowledge as well as their imagination to arrive at meaning.

One possible pedagogical implication of this study with regard to the findings is not that we should divide different learners based on their experiential learning styles and then provide them with different instruction content. Instead, and as ELT posits, effective learners are able to adapt their learning styles according to the 
demands of different learning tasks (Kolb, et al., 2001). To the extent that the individual learning preferences are respected and recognized, it is also important for the students to be exposed to diverse instructional focuses where their foreign language learning abilities and competencies can go beyond the their preferred learning modes. Many studies have shown students shift their learning styles to match the learning demands of a particular instructional mode (Kolb, 1984).

The point made in the paragraph above is not meant to deny the learners of their rights to be informed of their naturally stronger learning styles. As an important pedagogical implication of this study it is suggested that students be assessed on their experiential learning at the outset of a foreign language instructional program. However, as mentioned earlier in this study, ELT is based on a number of propositions. According to Kolb (1984), learning is best conceived as a process, not in terms of outcomes. So, after informing learners of their most preferred learning style and its characteristics, they should also be informed of the effectiveness of going through the cycle of four stages so that they can maximize their learning potentials.

As an extension of the implication mentioned above, data on learners' learning styles can be used as a diagnostic tool. Students do need to be informed of their preferred learning styles and this information should be presented to researchers of foreign language learning difficulties, instructors and students alike. For researchers, the information about learning styles and its relation with learners differential achievement rates can help identify and diagnose specific language learning problems in students with difficulties. For instructors, they provide important information about how to address the needs of the students. For students, this information allows them to be active participants in their learning by recognizing their strengths and weaknesses.

\section{References}

Aghbar, A. (1990). Fixed expressions in written texts: implications for assessing writing sophistication. Paper presented at a meeting of the English Association of Pennsylvania State System Universities.

Al-Zahrani, M. (1998). Knowledge of English lexical collocations among male Saudi college students majoring in English at a Saudi university. Unpublished doctoral dissertation, Indiana University of Pennsylvania, Pennsylvania.

Benson, M., Benson, E., \& Ilson, R. (1986). The BBI combinatory dictionary of English. Amsterdam: John Benjamins Publishing Company.

Biskup, D. (1992). L1 influence on learners' renderings of English collocations: A Polish/German empirical study. In P. J. L. Arnaud, \& H. Bejoint (Eds.), Vocabulary and applied linguistics (pp. 85-93). London: Macmillian.

Castro, O., \& Peck, V. (2005). Learning styles and foreign language learning difficulties. Foreign Language Annals, 38(3), 410-9. http://dx.doi.org/10.1111\%2Fj.1944-9720.2005.tb02226.x

Channell, J. (1981). Applying semantic theory to vocabulary teaching. ELT Journal, 35(2), 115-122. http://dx.doi.org/10.1093\%2Felt\%2FXXXV.2.115

Claxton, C. S., \& Ralston, I. (1978). Learning styles: Their impact on teaching and administration. Washington DC: National Institute of Education.

Conklin, K., \& Schmitt, N. (2007). Formulaic sequences: Are they processed more quickly than nonformulaic language by native and nonnative speakers? Applied Linguistics, 28, 1-18. http://dx.doi.org/10.1093\%2Fapplin\%2Famm022

Decarrico, J. (2001). Vocabulary Learning and Teaching. In M. Celce-Murcia (ed.) (2001), Teaching English as a Second or Foreign Language (3rd ed). Heinle \& Heinle: Boston. pp. 285-300.

Ehrman, M., \& Oxford, R. (1988). Ants and grasshoppers, badgers and butterflies: Qualitative and quantitative exploration of adult language learning styles and strategies. Paper presented at the Symposium on Research Perspectives on Adult Language Learning and Acquisition, Ohio State University, Columbus, $\mathrm{OH}$.

Erman, B., \& Warren, B. (2000). The idiom principle and the open choice principle. Text, 20(1), 29-62. http://dx.doi.org/10.1515\%2Ftext.1.2000.20.1.29

Firth, J. R. (1957). A synopsis of linguistic theory 1930-55. Studies in Linguistic Analysis (special volume of the Philological Society) (pp. 1-32). The Philological Society, Oxford. [Reprinted in: Palmer, F. R. (ed.) (1968), Selected Papers of J. R. Firth 1952-59 (pp. 168-205). Longmans, London.]

Fontenelle, T. (1994). What on earth are collocations: an assessment of the ways in which certain words co-occur and others do not. English Today, 10(4), 42-48. 
Foster, P. (2001). Rules and routines: A consideration of their role in the task-based language production of native and non-native speakers. In M. Bygate, P. Skehan, \& M. Swain (Eds.), Researching pedagogic tasks (pp. 75-93). Harlow, England: Pearson Education.

Geiger, M. (1992). Learning styles of introductory accounting students: An extension to course performance and satisfaction. Accounting Educators' Journal, 4(1), 22-39.

Gitsaki, C. (1996). The Development of ESL Collocational Knowledge, Ph.D. thesis, Center for Language Teaching and Research, The University of Queensland, Brisbane, Australia.

Howarth, P. (1998). Phraseology and second language proficiency. Applied Linguistics, 19(1), 24-44. http://dx.doi.org/10.1093\%2Fapplin\%2F19.1.24

Hsu, J. (2002). Development in collocational proficiency in a workshop on English for general business purposes for Taiwanese college students. Unpublished doctoral dissertation, Indiana University of Pennsylvania, Pennsylvania.

Kinsella, K. (1995). Understanding and empowering diverse learners in ESL classrooms. In J. M. Reid (Ed.), Learning styles in the ESL/EFL classroom (pp.170-194). Boston, MA: Heinle \& Heinle.

Kolb, D., Boyatzis, C., \& Mainemelis, C. (2001). Experiential learning theory: Previous research and new directions. In R. J. Sternberg, \& L. Zhang (Eds.), Perspectives on thinking, learning, and cognitive styles (pp. 227-247). London, UK: Routledge.

Kolb, D. A. (1999). Bibliography of research on experiential learning theory and the Learning Style Inventory. Department of Organizational Behavior. Weatherhead School of Management, Case Western Reserve University, Cleveland, $\mathrm{OH}$.

Kolb, D. A. (1976). Learning Style Inventory. Boston, MA: Hay Group, Hay Resources Direct.

Kolb, D. A. (1984). Experiential Learning: Experience as the Source of Learning and Development. Prentice-Hall, Inc. Englewood Cliffs, NJ.

Long, M. (1991). Focus on form: A design feature in language teaching methodology. In K. de Bot, R. Ginsberg, \& C. Kramsch (Eds.), Foreign language research in cross-cultural perspective (pp. 39-52). Amsterdam: John Benjamins.

Martyńska, M. (2004). Do English language learners know collocations? Investigations Linguisticae, 11. Retrieved May 1, 2007 from http://www.staff.amu.edu.pl/*inveling/pdf/malgorzata_martynska_inve11.pdf

McCarthy, B. (1996). The 4MAT system: Teaching to learning styles with right/left mode techniques. Oak Brook, IL: EXCEL.

Milton, J. (2009). Measuring second language vocabulary acquisition. Bristol, England: Multilingual Matters.

Nation, P. (2001). Learning vocabulary in another Language. Cambridge: Cambridge University Press.

Nattinger, J. (1988). Some current trends in vocabulary teaching. In R. Carter, \& M. McCarthy (Eds.), Vocabulary and Language Teaching (pp. 62-82). London \& New York: Longman.

Nel, C. (2008). Learning style and good language learners. In C. Griffiths (Ed.), Lessons from good language learner (pp. 49-60). Cambridge: Cambridge University Press.

Reid, J. M. (1998). Understanding learning styles in the second language classroom. Upper Saddle River, NJ: Prentice-Hall.

Veres, J. G., Sims, R. R., \& Locklear, T. S. (1991). Improving the Reliability Of Kolb's Revised Learning Style Inventory. Educational and Psychological Measurement, 57(1), 143-150. http://dx.doi.org/10.1177\%2F0013164491511013

Webb, S., \& Kagimoto, E. (2009). The effects of vocabulary learning on collocation and meaning. TESOL Quarterly, 43, 55-77.

Zughoul M., \& Abdul-Fattah, H. (2003). Collocational strategies of Arab learners of English: A study in lexical semantics. Retrieved from ERIC database. http://dx.doi.org/10.1075\%2Fbabel.49.1.05zug 